\title{
Design of E - commerce Double - type Talents Based on Top - level Design
}

\author{
Xiao Jianhua \\ School of Economics and Management \\ Wuyi University, Jiangmen \\ Guangdong 529020, China
}

\begin{abstract}
In order to solve the lack of top-level design in the process of e-commerce professional training in ordinary colleges and universities, this paper constructs the double-type ecommerce under the view of the whole industry chain from the aspects of providing top-level design basis and analyzes the status situation of professional construction and designing talent cultivation scheme talent training system. Practice has proved that the initiative of student learning improves obviously and the training of professionals is more suitable for social needs.
\end{abstract}

Keywords-Top-level design; The whole industry chain; Double creation; Personnel training

\section{RAISE QUESTIONS}

Professional construction of the top design is to make sure talent training objectives and make the development of personnel training program [1]. Professional construction can achieve results, doing the top design is essential.

Most of the ordinary colleges and universities, especially the second-batch universities represented by the local universities, often lack the top-level design of the professional construction in the process of formulating the personnel training program. The analysis of the orientation of the personnel training of the school, the positioning of the market and the orientation of the discipline Not enough, the status of the professional construction is also not thorough understanding, which will inevitably lead to fuzzy thinking of personnel training, target positioning is not clear [2]. At the same time, it will inevitably lead to colleges and universities personnel training programs much the same, and is even different from the vocational. It also makes too much emphasis on the specific operation of e-commerce, the overall level is not high.

The last is that we need to analyze the subject positioning, which includes: the professional talent training requirements of Ministry of Education Instruction Committee; related subject characteristics and development trend; the development trend of the domestic and foreign electronic commerce specialty.

\section{PROVIDE TOP-LEVEL DESIGN BASIS}

Top-level design is based on two aspects, one is positioning analysis, and the second is the status quo analysis.

\section{A. Positioning analysis}

As shown in Figure 1, positioning analysis is including school personnel training target positioning, market positioning and disciplinary positioning

The first is to understand the school level of personnel training target positioning. Wuyi University talent training target positioning is "to actively adapt to the regional economic and social development needs, through the integration of production and education, school-enterprise cooperation, training with innovative entrepreneurial ability of high-quality compound talents."

The second is to analyze the professional market positioning, including: analysis of domestic and international development of e-commerce industry trends and trends; analysis of the country, Guangdong Province, Pearl River Delta, Jiangmen on the demand for e-commerce talent.

Finally, it is necessary to analyze the disciplines of ecommerce professional, including: the Ministry of Education Teaching Steering Committee of the professional personnel training requirements; related disciplines and development trends; domestic and international e-commerce professional development trends.

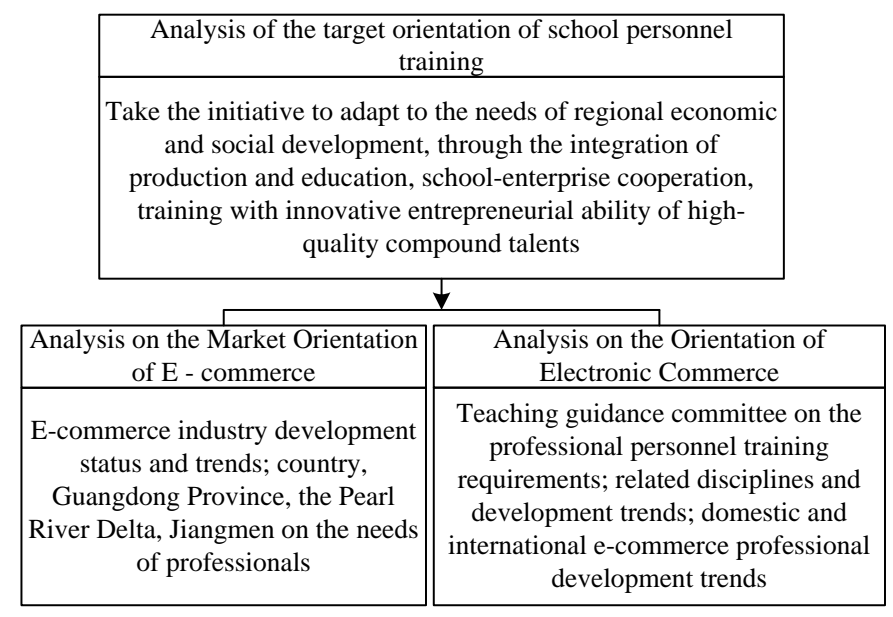

Fig. 1. Location analysis 


\section{B. Analysis on the Existing Problems of Professional Personnel Training}

As shown in Figure 2, the professional is mainly through the following four aspects of information to clarify the professional personnel training existing problems: the relevant teaching units and teachers of the feedback; the professional annual "talent training objectives, Process monitoring and quality evaluation committee "evaluation opinion; employing units of the professional personnel training effect feedback; with the same type of school e-commerce professional construction of the situation comparison.

Among them, "Personnel Training Objectives, Process Monitoring and Quality Evaluation Committee" is Wuyi University e-commerce professional to ensure the scientific and effective reform of personnel training, by the Ministry of Education Teaching Steering Committee of the leading experts, comprehensive " Five forces and the formation of its mission is to achieve the entire process of personnel training, and the annual "talent training objectives, process monitoring and quality evaluation meeting" to achieve the results of the year in a timely manner, the problems encountered Timely solution to protect the professional construction along the right track fast forward.

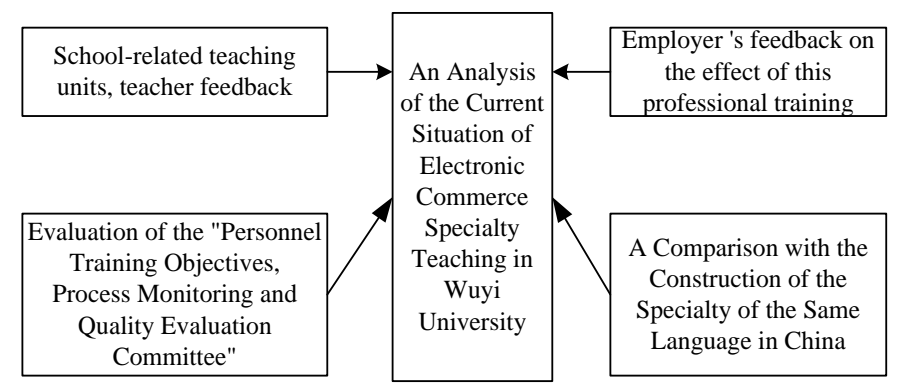

Fig. 2. Analysis of problems about personnel training

\section{DEVELOP A TALENT TRAINING PROGRAM}

As shown in Figure 3, this stage is to do four progressive work [1]: first in the previous stage on the basis of work to determine the positioning of personnel training objectives; the second is to ensure the realization of target positioning, build a good "Knowledge, ability and quality" model; third is in accordance with the "knowledge, ability and quality" model design training system; Finally, on the basis of the above, personnel training program form:

\section{A. Determine the goal of personnel training}

Considering the following factors: clothing is Jiangmen City's the traditional industry; clothing is the most suitable for e-commerce sales of one of the products and the need for professional knowledge is relatively easy to grasp; Wuyi University clothing professional have advantages that it is the only master point in south China; mobile commerce is the future of the development of e-commerce industry focus areas. Set two professional direction: clothing e-commerce, mobile ecommerce, the former partial marketing, the latter heavy technology, but also in line with the Ministry of Education ecommerce instructor of the guiding spirit.

Thus, in the two characteristics of the direction, we should base on the clear positioning of personnel training objectives: make development of mobile commerce technology or apparel products network marketing with core competitiveness, make electronic commerce talented person able to do the marketing manager or technical director of upper mesosphere jobs.

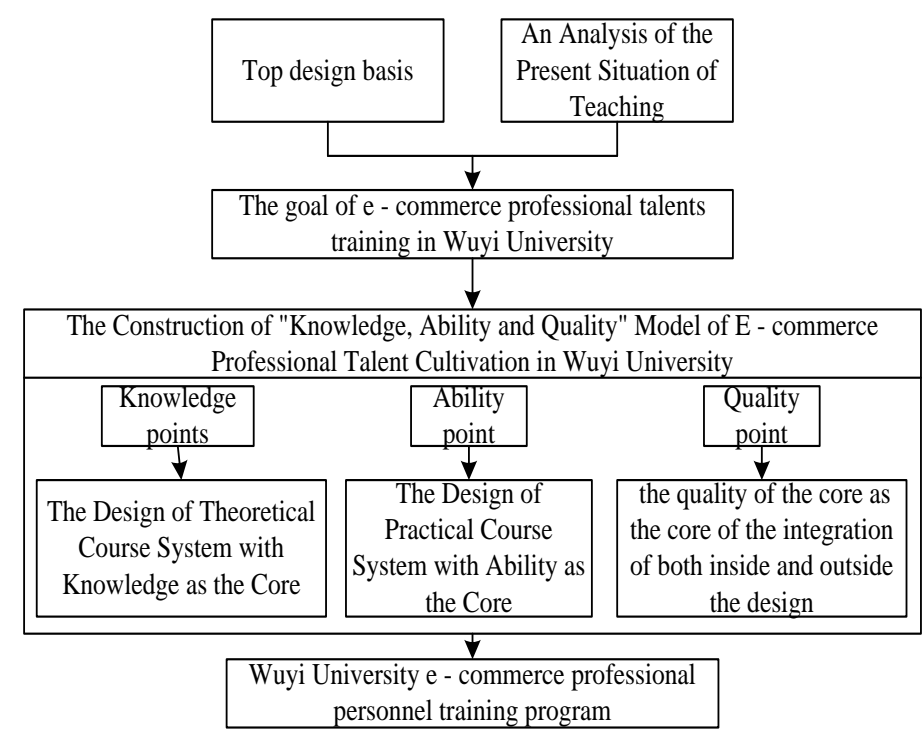

Fig. 3. Ideas about talent training program

\section{B. Construct "knowledge, ability and quality model"}

According to the Ministry of education teaching guidance committee requirements, the regional economic development, the electronic commerce of Wuyi University students characteristics are in three aspects, the construction of professional knowledge, ability and quality system, as shown in figure 4 .

In Figure 4, personalized knowledge units are mainly implemented by setting up four major classes (art, clothing, mobile, Entrepreneurship) special courses, and through the characteristic courses to achieve professional core competitiveness. Professional cultural construction is a major feature of the quality education of e-commerce major in Wuyi University. 


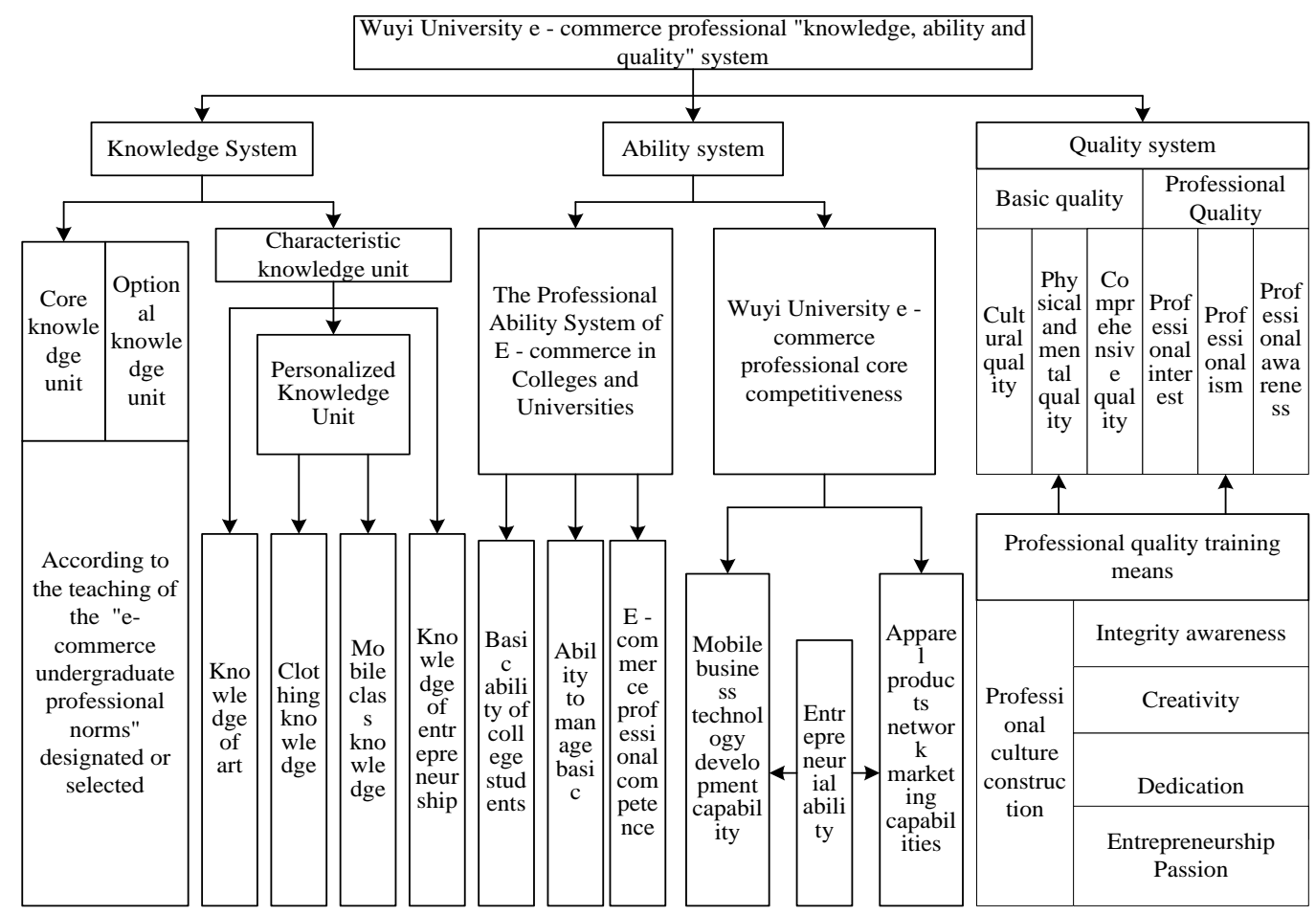

Fig. 4. Wuyi University e-commerce professional "knowledge, ability and quality" model

\section{Construct the curriculum system from the perspective of the whole industry chain}

Intuitively, the whole industry chain is consumer-oriented and starting from the source of the industry chain, through the production and procurement, trade and logistics, product information dissemination, customer problem solutions, user experience, after-sales service and tracking, and so on, In addition to the source of the product flow process can be traced back, but also the formation of pre-sale, after-sales, the upper and lower links link the whole process [3].

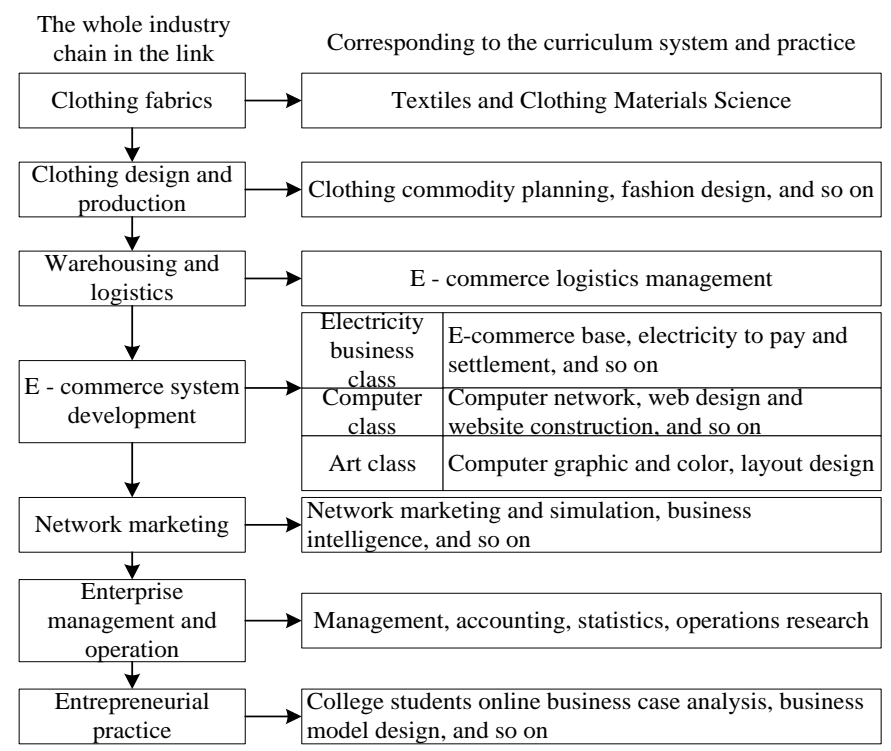

Fig. 5. The direction curriculum system of the whole industry chain perspective "apparel e-commerce"
Each industry there is the industry's industrial chain, enterprises only efficient integration of all links in the industry chain in order to obtain a dominant position in the market [4]. As a new thing in e-commerce, to find the future development of the commanding heights, naturally can not escape the exploration of the whole industry chain.

Combined with Wuyi University e-commerce professional "knowledge, ability and quality" model, the use of the whole industry chain perspective, in accordance with the two characteristics of the direction: clothing e-commerce, mobile ecommerce, curriculum system [5]. "Clothing e-commerce" direction as an example: "clothing e-commerce" The entire industry chain includes: clothing fabrics (including fabrics, accessories), clothing design and production, warehousing and logistics, e-commerce system development and network marketing, business management and operations along this industry chain, design courses are as shown in Figure 5.

\section{TALENT TRAINING EFFECTIVENESS}

Under the guidance of the experts of the Teaching Steering Committee of the Ministry of Education, we have cooperated with enterprises, industry associations, government departments, and brothers' institutions, and adopted the teaching mode of "teaching and learning fusion" to make the teaching, competition and innovation, Entrepreneurship "four in one.

Through the teaching reform, the students 'learning motivation is significantly improved, the students' "double hit" consciousness and the "double creation" ability are effectively improved. Finally, the employment of the students has also been improved obviously. 
According to the authority of the third party agencies Maike Si's the "Wuyi University graduates training quality evaluation report (2016)", Wuyi University e-commerce graduates regardless of the employment rate, and the quality of employment are very good : Graduates of Wuyi University 's non-unemployment rate is $93.2 \%$, e-commerce graduates is $100 \%$ in 2015; Wuyi Universitys' graduates earn 4094 yuan half a year after later, e-commerce graduates earn 4928 yuan which is higher than $20.4 \%$ compared to the school average, and is higher than the management of professional average (4013 yuan) $22.8 \%$ higher, in all liberal arts, science, management and professional category ranked first, but also more than most of the engineering; Wuyi University e-commerce Professional 2015 graduates earn 4928 yuan half a year later, the national similar non-"211" institutions of electronic business professional average of 4086 yuan, Wuyi University is $20.6 \%$ higher.

\section{ACKNOWLEDGMENT}

Author information: Xiao Jianhua, doctor, Professor, contact number: 13664917201 ,

e-mail: jianhuaxiao1@126.com.

This research is supported by the following project support: Guangdong Province Education Research "12th Five-Year" project, based on the cooperation of Guangdong province talent of Electronic Commerce (2013JK173); model innovation project of fostering talents of Guangdong Province in the experimentation area, e-commerce talent training mode of innovative combat experimentation area (GDJX2016004).

\section{REFERENCES}

[1] Yu Jian. Top level design on comprehensive reformation of air transport management major. Journal of Civil Aviation University of China. Vol.30, No. 5, 2012, pp.27-33.

[2] Fu Jie. Research on online to business cultivation major majority of ecommerce. Heilongjiang Science. Vol.7 No.9, 2016, pp.152-153.

[3] Zhang Xiao-lin, Yu Zhan-ping. Research on whole industrial chain mode in innovation of agricultural production-marketing system. Journal of Beijing Technology and Business University (Social Sciences) Vol.28 No.59, 2013, pp .14-17.

[4] Hao Shimian, Wang Weizhong, Shen Manman. Three-dimensional risk assessment of the whole food industry chain. Statistics and decisionmaking, 2017 (11): 38-41

[5] Zhao Lianghui, Xiao Jianhua, Bian Yungang. Reform and Practice of Ecommerce Training Program in Applied University E-business Journal. 2013 (7): 65-67. 